Dez 2017 - v.7 - n.2

\title{
Uso de Células-Tronco fetais no tratamento da leucemia
}

No Brasil e em todo o mundo, há pacientes que sofrem com doenças onco-hematológicas, a exemplo de Mielofibrose primária, Mieloma múltiplo, Leucemia e outras patologias, e diariamente nos diversos meios de comunicação, ouvimos falar sobre o congelamento do sangue do cordão umbilical, e isso se dá pelo seu potencial terapêutico. Também se sabe que a extração de Células-Tronco embrionárias ainda é discutida em debates éticos, ao passo que a obtenção de Células-Tronco retiradas diretamente da medula óssea causa certa aversão e temor à população,; além disso, ratifica-se que as Células-Tronco adultas têm suas diversas fontes limitadas. Nisto, encaixa-se as Células-Tronco fetais; essas podem gerar uma cópia idêntica para distingui-la em vários tipos de tecidos. É a sua natureza que, como as células estaminais fetais, são classificadas como adultas e podem ser removidas do cordão umbilical e placenta. Levando em consideração esses aspectos, este trabalho irá contribuir com a comunidade científica pelo fato de enfatizar que as Células-Tronco fetais resignam os empecilhos que as Células-Tronco embrionárias e as Células-Tronco adultas provindas da medula óssea, e outras fontes, apresentam. O trabalho será desenvolvido com base em uma pesquisa bibliográfica, qualitativa, descritiva e exploratória, sendo utilizados livros, revistas e artigos referentes ao assunto estudado.

Palavras-chave: Células-Tronco; Medula óssea; Leucemia.

\section{Use of fetal stem cells in the treatment of leukemia}

In Brazil and around the world, there are patients suffering from onco-hematological diseases, such as primary myelofibrosis, multiple myeloma, leukemia and other pathologies, and daily in the various media, we hear about the freezing of umbilical cord blood , and this is due to its therapeutic potential. It is also known that the extraction of embryonic stem cells is still discussed in ethical debates, whereas obtaining stem cells withdrawn directly from the bone marrow causes a certain aversion and fear of the population; furthermore, it is confirmed that adult stem cells have their various limited sources. In this, Fetal Stem Cells fit; these can generate an identical copy to distinguish it in several types of fabrics. It is their nature that, like fetal stem cells, are classified as adult and can be removed from the umbilical cord and placenta. Taking into account these aspects, this work will contribute to the scientific community by emphasizing that fetal stem cells resent the obstacles that embryonic stem cells and adult stem cells from bone marrow and other sources have. The work will be developed based on a bibliographical, qualitative, descriptive and exploratory research, being used books, magazines and articles referring to the studied subject.

Keywords: Stem cells; Bone marrow; Leukemia.

\section{Topic: Hematologia e Hemoterapia}

Reviewed anonymously in the process of blind peer
Received: 07/12/2017

Approved: 14/12/2017

Jéssica Diniz Aguiar

Faculdade Guaraí, Brasil

http://lattes.cnpq.br/9871264965411643

jessicadiniz467@gmail.com

Simone Possas Andrade

Faculdade Guaraí, Brasil

http://lattes.cnpq.br/0552128506796918

simomissag@hotmail.com

\section{Referencing this:}

AGUIAR, J. D.; ANDRADE, S. P.. Uso de Células-Tronco fetais no tratamento da leucemia. Scire Salutis, v.7, n.2, p.74-82, 2017. DOI: http://doi.org/10.6008/SPC2236-9600.2017.001.0009

DOI: 10.6008/SPC2236-9600.2017.002.0009 


\section{INTRODUÇÃO}

A habilidade de diferenciação em alguma célula especializada de qualquer tecido ou órgão é reservada às Células-Tronco, que são células capazes de atribuir-se características de uma mesma linhagem. Esta renovação se dá por meio da divisão celular, levadas assim, a formar células do corpo (ZORZANELLI et al., 2017).

Sabemos que hodiernamente podemos deparar-nos com a ideia do congelamento do sangue do cordão umbilical, por seu potencial terapêutico e abundância em Células-Tronco Fetais (CTFs). As vantagens são incontáveis, sendo capaz de alcançar até mesmo doenças como a Leucemia, que é um câncer oncohematológico (câncer no sangue). Podendo assim, substituir muitos transplantes de medula óssea (BOAVENTURA et al., 2014). Nesse sentido, vale ressaltar que o procedimento de coleta do sangue do cordão umbilical, não é invasivo (indolor) além de não depositar quaisquer riscos para mãe e a criança. Assim, uma das primícias para a coleta de Células-Tronco é a anamnésia, no qual diz respeito à obtenção de informações dos doadores, tanto do bebê quanto da mãe (LOPES et al., 2016).

Desse modo, a sinalização descrita no prontuário se constitui de um importante elemento a ser observado pela equipe médica, pois indica que há doador em potencial, sendo que, por conseguinte, sobrevém o acondicionamento (pós-coleta) adequado, e por fim, encaminhamento unidades devidamente preparadas e licenciadas a receber o material (LOPES et al., 2016).

Salienta-se ainda que as CTFs são consideradas células puras, pois não houve contato com o meio extrínseco, tais como: poluições, infecções, radiações e outros. Sendo assim, por sua carga inviolada, as chances de rejeição são inferiores às outras fontes de Células-Tronco, como as que são provindas da medula óssea, abraçando a possibilidade da viabilidade e compatibilidade do paciente que precisa submeter-se a esta terapia (ZORZANELLI et al., 2017).

Acresce-se ainda que as CTFs apresentam pequena possibilidade de rejeição quando comparadas às Células-Tronco hematopoiéticas encontradas na medula óssea, equivalendo a um percentual de um a cada vinte mil indivíduos para uma medula óssea, contrapondo-se a um a cada quatro mil, quando se trata de células tronco do cordão umbilical (HIWARKAR et al., 2015).

A doação diretamente da medula óssea ainda é tida com grande receio por parte da população, em razão do método invasivo de extração celular, além da limitação das Células-Tronco adultas retiradas de outras fontes (limitação referida às variações celulares), sendo que, englobado a isto, fica evidente a existência de uma discussão ética e sistemática a respeito das Células-Tronco, especialmente, as embrionárias, pondo em questão onde realmente se inicia e se pode ser considerado vida (EVANS, 2014).

Dessa forma, justifica-se esse trabalho, pelo fato de que as CTFs resignam os empecilhos que as Células-Tronco Embrionárias e Células-Tronco Adultas provindas da medula óssea, e as de outras fontes, apresentam. $\mathrm{O}$ acentuado número de pessoas que sofrem com a Leucemia o e o número de mortes por conta desta doença pode ser reduzido de forma eficaz, fornecendo a regeneração celular. Os benefícios do incentivo à esta pesquisa, estendem-se a outras patologias, sendo assim, promessa para o progresso na 
saúde e na ciência. O presente projeto tem como objetivo abordar sobre o uso de Células-Tronco fetais no tratamento da Leucemia.

\section{METODOLOGIA}

O trabalho foi desenvolvido com base em uma pesquisa bibliográfica, qualitativa, descritiva e exploratória, sendo utilizados livros, revistas e artigos e sites tais como Scientific Electronic Library Online (SCIELO), Google Acadêmico e Biblioteca Virtual em Saúde (BVS). Foi feita esta pesquisa durante os meses de junho a outubro de 2017, utilizando as seguintes palavras-chave: Células-Tronco Fetais, Medula óssea, Bioética e Leucemia. Depois de realizada a busca de dados online, foi feita uma seleção dos artigos que se adequavam ao tema proposto e que apresentavam informações atualizadas e concisas sobre a temática proposta.

\section{DISCUSSÃO TEÓRICA}

De forma a contribuir no combate ao câncer como terapia, o ramo da biologia celular auxilia pesquisadores desde 1800, com a descoberta do microscópio, e, através do aparelho, pode-se proporcionar a diferenciação celular, reconhecendo, assim, sua importância para a vida. Dessa maneira, através de pesquisas científicas, pode-se conhecer a existências de células pluripotentes, no qual são capazes de se especializar em qualquer uma das células de todos os tecidos do organismo (ALBERTS, 2010).

Assim, a partir da década de 1950, com o aperfeiçoamento da ciência e da tecnologia, tornou-se possível a realização de transplantes de Células-Tronco da medula óssea, sendo utilizadas na cura de patologias do sangue, transplante de órgãos com mal funcionamento ou nenhum, de um devido paciente pelo órgão sadio de um doador (ZORZANELLI et al., 2017).

Já as Células-Tronco Embrionárias foram descobertas em 1980 em camundongos, quando foram retirados os blastos do embrião e conservados em laboratório, destacando-se e mantendo a sua plenipotência. Ao se pôr em prática a utilização nos camundongos imunodeficientes, houve-se um processo de diferenciação, em que foram fabricados os teratomas (espécie de tumor misto de diversos tecidos), demonstrando assim, a capacidade plenipotente das Células-Tronco Embrionárias. Em consequência disso, sabe-se que as Células-Tronco adultas podem gerar apenas alguns tipos particulares de células, mas as embrionárias têm a capacidade de gerar todas, em suas particularidades e peculiaridades (ZORZANELLI et al., 2017).

Portanto, foi no fim da década de 1990 que foi descoberto na medula óssea a existência de outros tipos de Células-Tronco adequadas para regenerar tecidos e órgãos, como por exemplo, o coração, fígado e sistema nervoso. Estas descobertas ofereceram abertura a pesquisas em busca de um número maior de novas terapias com Células-Tronco, para patologias como infarto, diabetes, cirrose hepática e lesão da medula óssea (SENEGAGLIA, 2009). 
Por conseguinte, foi descoberto no sangue contido no cordão umbilical, mais uma grande fonte de Célula-Tronco. Foram realizados inumeráveis estudos, pesquisas e utilização em milhares de transplantes, e foi do sangue obtido pelo cordão umbilical, que consagrou esta mesma fonte, para o tratamento de tantas patologias. Sendo resguardado pela resolução RDC 153/204, publicada em 14 de junho de 2004 pela Agência Nacional de Vigilância Sanitária (ANVISA), determinando todo o regulamento necessário de coleta, armazenamento, testes, processamento, controle de qualidade e transporte. Determinando o material obtido de fontes como: sangue venoso, medula óssea e as células oriundas do cordão umbilical placenta. Nela está contida também, determinantes quanto a distribuição do produto (BARBOSA et al., 2017).

Dentre os métodos de tratamento da Leucemia, destacam-se, quimioterapia, radioterapia e a utilização de Células-Tronco. Tendo a quimioterapia uma aplicação que utiliza muitas substâncias químicas agindo como interferentes na multiplicação das células danosas, malignas (ANDRADE, 2013). Realizada no tratamento contra doenças causadas por agentes biológicos, a Quimioterapia é uma terapia intensiva. Quando relacionada ao câncer, é chamada de quimioterapia antineoplásica, sendo seus compostos químicos chamados quimioterápicos. Ao submeter-se a estes tratamentos, tem-se dentre seus resultados a consequência de efeitos colaterais chegando a níveis de alto peso nos pacientes, devido à morte celular (BORGES, 2017).

Já a Radioterapia, tem como mecanismo de ação a área mais específica da região cancerosa, direcionando os raios ionizantes para os locais onde há maior concentração de células danosas, região a ser tratada. O tratamento através da radioterapia é dado por dosagens calculadas, em determinado volume e tempo, no qual variam de indivíduo para indivíduo. Ao entrar em contato com as células cancerígenas, os raios ionizantes, por se constituírem de feixes eletromagnéticos, se interrelacionam com os tecidos, originado a ionização do local através de elétrons rápidos possibilitando a ruptura das cadeias de ADN o que vai gerar, por consequência, morte celular (SOUZA, 2017).

Por mais restrita e específica que a radioterapia seja, os efeitos causados por este tratamento são ofensivos, atacando até mesmo as células que não são cancerígenas, ou seja, células saudáveis. Agudos ou até mesmo tardios, esses efeitos causam desconfortos e empecilhos aos pacientes que são limitados em suas atividades normais. Contudo, estes efeitos são limitados ao local da exposição da radioatividade (SOUZA, 2017).

Salienta-se também o tratamento com Células-Tronco, no qual são caracterizadas por três atributos: autorrenovação, por sua capacidade em originar Células-Tronco iguais; diferenciação em diversos tipos de linhagens celulares; ou ainda por possuir também a capacidade de dar origem as células funcionais nos tecidos derivados da mesma ascendência. Sendo assim, são células indiferenciadas capazes de se diferençar originando progenitores maduros assim como células efetoras inteiramente diferenciadas (ZORZANELLI et al., 2017).

A partir da Célula-Tronco, outras células são geradas, ou seja, cópias idênticas a si mesmas com aptidão de distinguir-se em vários tecidos. Quanto ao que se referem em sua natureza, as Células-Tronco- 
Fetais estão classificadas como adultas, e podem ser retiradas tanto do cordão umbilical quanto da placenta. São consideradas adultas devido a sua limitação quanto a diferenciação para a regeneração celular (HIWARKAR et al., 2015).

As Células-Tronco Fetais (CTFs), do mesmo modo como as adultas se diferenciam, mas não tão espontaneamente quanto as embrionárias. Nesse mecanismo a transformação de uma linhagem a outra ocorreria exatamente a partir da ativação de um adjacente de genes que transformaria a especificidade celular. Mesmo diante disto, as CTFs proporcionam maior potência de auto renovação, diferente de outros originadores de Células-Tronco adulta (HIWARKAR et al., 2015).

É certo que as informações genéticas não se limitam a transcrição da mensagem que será codificada, o que ocorre do DNA para RNA que adiante fará a tradução em proteínas. Para que haja a expressão de determinado adjacente de genes ocorre inibição ou indução da transcrição de certo gene. Há uma espécie de espelho quando se ocorre a Transcrição do estado fisiológico em que a célula se encontra. Diante disto, será grandemente variante, pois atenderá as necessidades do momento determinado. Tal variabilidade se reflete no fato de que somente um gene ou grupo de genes em particular é transcrito naquele instante fisiológico, além dos processamentos do RNA e da regulação da atividade gênica estarem ocorrendo (ZATZ, 2004).

Expressando em sua superfície, as CTFs realizam as interações célula-célula e célula matriz. Os mecanismos de sinalização celular são fundamentais no procedimento de diferenciação celular, pois, quando as células tronco se dividem podem dar origem a uma célula filha igual e seguintes mais especializadas, é de acordo com o meio que será identificada a necessidade, em outras palavras, a qual célula ela deve se especializar (DIAS, 2016).

A patologia na qual as CTFs dispõem de ação terapêutica está inclusa dentre as patologias oncohematológicas, como a Leucemia, que é uma doença neoplásica caracterizada como maligna, a maneira como se desenvolve pelo organismo é ágil e rápida, sendo categorizada como mieloide ou linfoide e podendo expressar-se de forma aguda ou crônica. A Leucemia origina-se na medula óssea com a proliferação desregulada de um clone de células hematopoiéticas, com alterações na maturação e apoptose celular (DIAS, 2016).

Os pacientes que sofrem a patologia oncológica do sague, Leucemia, apresentam uma fabricação excessiva de leucócitos em estado atípico. Há a diminuição continua da geração de células normais, tendo como consequência o surgimento de infecções, anemias, e até mesmo hemorragias, estando sujeito a suportar alguns sintomas, tais como: Algias ósseas, fatiga, tontura, debilidade (sintomas claramente associados a anemia, mas que por vezes podem ser confundidos com osteoporose, prejudicando o tratamento de início). Diante da omissão ao tratamento, podem levar à morte do paciente (DIAS, 2017).

A leucemia aguda tem como primordial característica o excesso de produção de células jovens que são anormais, enquanto a crônica possui a produção exacerbada de células maduras. A medula é o centro de fabricação celular ocupando a cavidade dos ossos, (conhecida pela população como tutano). São encontradas 
na medula, células que vão dar origem aos glóbulos brancos, aos glóbulos vermelhos (hemácias ou eritrócitos) e às plaquetas (trombócitos).

Para o fechamento do diagnóstico da Leucemia são feitos alguns exames, em especial o Hemograma e o Mielograma. No Hemograma, é feita a análise das hemoglobinas, que se estiverem abaixo de $10 \mathrm{~g} / \mathrm{dl}$ mostra indicativo de uma anemia com diminuição de reticulócitos. Também no hemograma, o leucêmico pode apresentar no exame, trombocitopenia (diminuição das plaquetas). No mielograma é avaliado a morfologia, sendo ele: citoquímico, imunofenotípico e citogênico. Avaliando os blastos linfoides no sangue periférico ou na medula óssea, categorizando-se em: L1, L2 e L3 e demais especificidades. Na busca de resultados quanto ao citogenético são analisadas alterações cromossômicas (HIWARKAR et al., 2015).

Foi em 1988, quando se teve o início de pesquisas com resultados de grande relevância quanto ao uso do Sangue de Cordão Umbilical (SCU), sendo ele fonte de células reconstituidoras pela Dra. Eliane Gluckman, o que ocorreu na França. Foi possível realizar a terapêutica de um paciente de anemia de Fanconi, utilizando as Células-Tronco-Fetais de seu irmão afim de reabilitar as funções celulares após a quimioterapia. Pesquisa esta, que permitiu que as portas estivessem abertas para a busca do tratamento da Leucemia com a utilização dessas células (PRANKE, 2004).

No Reino Unido foi realizado uma pesquisa que mostrou a aplicação de CTFs no tratamento contra cânceres onco-hematológicos, incluindo a Leucemia. Estas pesquisas mostraram efeito maior do que as Células-Tronco extraídas de doadores adultos. Foi injetado o linfoma em ratos, e feita a comparação entre as células adultas e as fetais, comparando os efeitos de cada uma. Foi concluído que, as células cancerígenas em curto espaço de tempo foram eliminadas com a injeção de Células-Tronco que foram retiradas dos cordões umbilicais de neonatos (HIWARKAR et al., 2015).

As Células-Tronco adultas extraídas de outros locais contribuem, porém, com uma resposta inferior e a prazos mais longos neste processo de eliminação do câncer. Levando a crer que de fato, isto se dá por causa da rápida produção de células CD4, sinalizadoras do sistema imune ocorrendo a incitação pelas CTFs Afirma-se que: "Células-Tronco retiradas de cordões umbilicais também aumentaram a produção e a atividade de células CD8, responsáveis por eliminar tumores e células contaminadas por vírus e bactérias" (HIWARKAR et al., 2015).

Cada vez mais é notável no meio acadêmico a resposta da terapia em que se utiliza as Células Fetais, em pesquisas se pode notar que o sucesso em que o combate a Leucemia vem se crescendo deve-se não apenas ao diagnóstico precoce, mas também aperfeiçoamento terapêutico em que se utiliza o sangue de Cordão Umbilical e Placentário (ZORZANELLI et al., 2017).

Existe uma prevalência de artigos científicos que ao decorrer do tempo, estão sendo publicados na Revista Brasileira de Hematologia e Hemoterapia. A revista não apenas foca nas discussões éticas a serem argumentadas, mas também nas pesquisas quanto à terapia. Abordando em sua maior parte as perspectivas de utilização de tratamentos com as Células-Tronco da medula óssea bem como, as do sangue do cordão 
umbilical, para o devido tratamento de doenças cardíacas, oftalmológicas, reumáticas, doenças autoimunes, diabetes e leucemia (ZORZANELLI et al., 2017).

Nos casos de Leucemia, é factível recorrer ao transplante celular, sem descartar a quimioterapia e a radioterapia. Na Quimioterapia Antineoplásica, são usados os agentes químicos no tratamento do câncer afetam tanto as células normais quanto as anormais, ou seja, as neoplásicas. Sendo assim, ela causa mais agravos as células malignas neoplásicas. Enquanto ambas aniquilam células cancerígenas, o transplante de CTFs reconstitui as células que foram perdidas durante o processo. Fazendo com que o organismo tenha a produção de novas células imunes, reforçando a eliminação das células patológicas.

Segundo os pesquisadores, mesmo que consideradas células imaturas, as células sanguíneas descobertas no cordão umbilical de neonatos, além da reposição celular já citada, reconhecem e destroem células anormais no organismo do paciente, e sabendo-se que os quimioterápicos não agem somente nas células tumorais, mas também atingem a medula óssea, pelos, mucosa do tubo digestivo, estruturas normais que através das células tronco podem se renovar. Tais descobertas contribuem para o avanço cientifico e para passos mais competentes no tratamento do câncer (DIAS, 2016).

Utilizar as Células-Tronco de forma terapêutica no combate ao câncer tem tomado cada vez mais espaço, e é notório o seu crescimento à medida que as pesquisas evoluem e elucidam os saberes a respeito da melhor forma de tratamento. Torna-se cada vez mais claro que o transplante com as células presentes no cordão umbilical, vem sendo um dos melhores transplantes que possibilitam alta aceitação e receptividade por parte do paciente, no caso, o leucêmico receptor. Existe ainda maior compatibilidade quando o receptor é autólogo (DIAS, 2016).

Para que haja um filtro entre aquilo que é limite com relação à pesquisa, e a utilização de CélulasTronco, cabe à bioética a solução destes conflitos e discussões éticos, acerca dos transplantes de CélulasTronco. Tais conflitos resultam naturalmente da interação e convívio do ser humano em sociedade. Esta ciência embasa e resguarda a defesa pelos direitos humanos, evoluções de pesquisas científicas, proteção à vida, bem como o consentimento dos direitos e normatizações, propostas de forma geral para utilização destes meios (PEREIRA, 2015).

Existem aqueles que não concordam com a utilização de Células-Tronco embrionárias, crendo na vida desde a concepção, portanto, ao serem utilizados os embriões, são atingidos aqueles que por motivos morais, ou religiosos não estão de acordo com este método. Moraes (2003, citado por DORIGATTI, 2017) entende que "a Constituição Federal de 1988 e o Código Civil de 2002 não asseguram apenas a proteção à vida extrauterina, mas também a vida intrauterina desde o momento da concepção". Fundamentos a este conceito, tendem a serem afligidos com uso das Células-Tronco-Embrionárias (DORIGATTI, 2017).

Existe um empecilho ético e religioso no uso Células-Tronco oriundas dos embriões humanos. Neste contexto, são levados os questionamentos: o embrião é ou não um ser humano?; Permitir que as pesquisas que façam a utilização de embriões não poderiam arcar com o efeito consequente de comercializações de 
embriões humanos ou até mesmo em clonagem, fazendo com que embriões sejam apenas materiais biológicos em estudos científicos? (PEREIRA, 2015).

Geralmente as Células-Tronco adultas são muito utilizadas em pesquisas, bem como de forma terapêutica ao se tratar de diversas patologias. Por se tratarem de fontes que não acometem o ser humano, não há polêmica na prática da utilização. Entretanto a limitação se dá quanto a sua eficácia e habilidade em capacidade de transformação em diferentes tipos celulares, pois, não possuem a mesma versatilidade das células embrionárias (PEREIRA, 2015).

É certo que geralmente países em que a prática do uso de Células-Tronco embrionárias é permitida, há uma variação para outros campos, como a clonagem. Um exemplo disso é a Coréia do Sul, que desde o mês de fevereiro de 2004 tem divulgado que já fazem clonagens com embriões humanos, e que de 242 óvulos formaram-se 30 embriões, com cópias idênticas as de suas 16 doadoras (PIVETTA, 2005).

Já no Brasil, o debate entrou ainda mais em vigor na aprovação em março de 2005 quando a Lei de Biossegurança inclui a permissão do uso de Células tronco-embrionárias com finalidade em tratamentos e pesquisas. O uso dos embriões é restringido apenas àqueles que não seriam mais necessários para a reprodução assistida, inutilizável ou conservada há algum tempo (mais de três anos da data da publicação da lei), de forma que garanta o consentimento dos genitores para a utilização (AVELINO, 2009).

Foi inaugurado em 2001 o primeiro banco para doação de sangue umbilical e placentário sendo este o primeiro banco público no Brasil, o mesmo foi fundado pelo INCA no Rio de Janeiro. Tendo em vista, a redução das probabilidades de incompatibilidade de Células-Tronco do cordão, ou seja, do doador e do receptor. Levando a crer que se há aumento no número de doações, menores taxas de incompatibilidade (EITELVEN et al., 2017).

É neste contexto, que as CTFs se tornam alternativas nos casos de Leucemia, para os que não concordam com o uso Células-Tronco Embrionárias (discussões éticas envolvidas), para os que ainda possuem receio do método para se obter as Células Tronco Adultas da Medula Óssea, e para as limitações gerais das Células-Tronco adultas. (BOAVENTURA et al., 2014).

Diminuição do número de pessoas que sofrem com esse tipo de câncer e o regresso do número de mortes por conta desta doença, podem ser realizados eficazmente fornecendo a regeneração celular. A necessidade para o bem estar e saúde de toda a população, melhor recuperação dos pacientes com câncer, solução para outras patologias, e promessa para o progresso na saúde e na ciência demonstram a carga de vantagens que marcam a evolução cientifica (BOAVENTURA et al., 2014).

\section{CONCLUSÕES}

No Brasil e em todo o mundo, há pacientes que sofrem com doenças onco-hematológicas, tais como: Mielofibrose primária, Mieloma múltiplo, Leucemia e outras patologias. Os portadores de Leucemia, enfrentam muitas dificuldades mediante os conflitos éticos envolvidos, bem como a qualidade de vida, dificuldades que podem receber tamanha redução através das CTFs, podendo regredir acentuadamente nos 
próximos anos o crescimento destas patologias. Como um profissional a serviço da saúde, é fundamental que o Biomédico busque constantemente participar e estar ciente de assuntos que envolvam a Bioética, não apenas pelo campo da pesquisa, pois a Bioética se estende a todos os setores da saúde, tendo em vista que é uma ciência que vem a resguardar os direitos humanos.

\section{REFERÊNCIAS}

ALBERTS, B.; JOHNSON, J. A.; MORGAN, D.; RAFF, M.; ROBERTS, K.; WALTER, P.; WILSON, J.; HUNT, T.. Biologia molecular da célula. Porto Alegre: Artmed, 2010

ANDRADE, V.; SAWADA, N. O.; BARICHELLO, E.. Qualidade de vida de pacientes com câncer hematológico em tratamento Quimioterápico. Revista da Escola de Enfermagem da USP, v.47, n.2, p.355-361, 2013.

AVELINO, S.; DINIZ, J.. As Células-Tronco e os debates atuais. São Paulo: Atlas, 2009.

BARBOSA, S. O.; BALMANT, M. F.; NARDIN, J. M.; LIDANI, K. C.. Do doador ao receptor: o ciclo do sangue. Cadernos da Escola de Saúde, v.1, n.2, 2017.

BOAVENTURA, L. R.; TREVISIAN, J. A.. O uso de CélulasTronco do sangue de cordão umbilical e placentário no tratamento de leucemias em crianças. Núcleo

Interdisciplinar de Pesquisa, Brasília, v.1, n.2, p.2-5, 2014.

BORGES, K. O. R.. Qualidade de vida em pacientes submetidos à quimioterapia antineoplásica utilizando o instrumento EORTCQLQ-C30. Revista EM FOCO - Fundação Esperança/IESPES, v.2, n.26, p.14-26, 2017.

DORIGATTI, P. G.. O Direito à vida. Âmbito Jurídico, Rio Grande, v.19, n.151, 2017.

EITELVEN, T.; MENIN, R. P.; FUSIGER, K. C.; BENVENUTTI, V.; ZANINI, J.; CAUMO, C. R.. Aplicações biológicas de CélulasTronco: benefícios e restrições. Revista Interdisciplinar de Ciência Aplicada, v.2, n.3, p.16-25, 2017.

EVANS, M.. Riscos e benefícios das Células-Tronco. Pesquisa FAPESP, São Paulo, v.222, 2014.
HIWARKAR, P.; QASIM, W.; RICCIARDELLI, I.; GILMOUR, K.; QUEZADA S.; AMROLIA, P.; VEYS, P.. Cord blood T cells mediate enhanced antitumor effects compared with adult peripheral blood T cells. Blood, v.126, n.26, p.2882-2891, 2015.

LOPES, L. A.; BERNARDINO, E.; CROZETA, K.; GUIMARÃES, P. R.. Good practices in collecting umbilical cord and placental blood. Revista Latino-Americana de Enfermagem, v.24, 2016. DOI: http://doi.org/10.1590/1518-8345.0781.2770

PEREIRA, A. D.. A Bioética e os estudos com Células-Tronco. Altônia: UFPR, 2015.

PIVETTA, M.. Células-Tronco. Pesquisa Fapesp, São Paulo, v.4, p.36-6, 2005.

PRANKE, P.. A importância de construir bancos de sangue de cordão umbilical no Brasil. Ciência e Cultura, v.56, n.3, p.3940, 2004

SENEGAGLIA, A. C.; REBELATTO, C. L. K.; SUSS, P. H.; BROFMAN, P. R. S.. Expansão de Células-Tronco da medula óssea e do sangue de cordão umbilical humano. Revista Brasileira de Hematologia e Hemoterapia, v.31, n.1, p.9-14, 2009.

SOUZA, M. V.. Associação entre qualidade de vida e indicadores de atividade física e capacidade funcional em pacientes onco-hematológicos do Hospital Universitário de Florianópolis. Monografia (Graduação em Educação Física) Universidade Federal de Santa Catarina, Florianópolis, 2017.

ZATZ, M.. Clonagem e Células-Tronco. Estudos avançados, v.18, n.51, p.247-256, 2004.

ZORZANELLI, R. T.; SPERONI, A. V.; MENEZES, R. A.; LEIBING, A.. Pesquisa com Células-Tronco no Brasil: a produção de um novo campo científico. História, Ciências, SaúdeManguinhos, v.24, n.1, p.129-144, 2017. 